\title{
DESAIN JARINGAN DISTRIBUSI BERBASIS E-BUSINESS PADA SISTEM RANTAI PASOK
}

\author{
Fino Wahyudi Abdul ${ }^{1}$ \\ Institut Ilmu Sosial dan Manajemen STIAMI \\ Fakultas Ilmu Sosial dan Manajemen, Program Studi Logistik \\ Email : fino@stiami.ac.id \\ Yuli Evitha* \\ Institut Ilmu Sosial dan Manajemen STIAMI \\ Fakultas Ilmu Sosial dan Manajemen, Program Studi Logistik \\ Email : evitha@stiami.ac.id
}

ARTICLE INFO

Kata Kunci:

Supply Chain, Distribution Network, Distribution Design

\section{ABSTRACT}

In this paper, we provide a form of distribution network design and application in the field of e-commerce in the supply chain, with a distribution network design approach. Thus a good distribution network model can be determined in e-commerce business and provide quality service through the delivery period of equipment and materials to the consumer's location that is fast and low cost which can provide more competitive prices for customers. This is where the role of distribution is very important, because with the distribution of all materials both raw materials and finished products can be distributed to each party in need in the supply chain. In the supply chain itself there are several distribution designs available, namely Manufacturer Storage With Direct Shipping, Manufacturer of Storage with Direct Shipping and In-Transit Merge, Storage With Carrier Delivery Distributor, Storage With Last-Mile Delivery Distributor, Manufacturer Or Distributor Storage With Customer Pickup.

\section{PENDAHULUAN}

Jaringan distribusi pada sistem rantai pasok (supply chain system) merupakan salah satu hal yang mendasar dalam penetapan keunggulan kompetitif jangka panjang. Mutu, rekayasa, produk, harga, lembur, kapasitas berlebih, kemampuan merespon pelanggan akibat kinerja kurang baik, waktu tenggang (lead time) dan profitabilitas keseluruhan adalah hal-hal yang dipengaruhi oleh tingkat persediaan.Perusahaan yang memiliki jaringan distribusi yang handal daripada pesaing cenderung berada dalam posisi kompetitif yang kuat. Kebijaksanaan manajemen distribusi telah menjadi salah satu senjata untuk memenangkan kompetitif. 
Didalam kegiatan manajemen rantai pasok (supply chain management) persoalan persediaan logistik mempunyai peran penting karena masalah-masalah pada bagian produksi tergantung pada persediaan bahan baku (row material) yang selalu tersedia. Bila produksi terganggu maka pengiriman barang kepada pelanggan juga terganggu yang mengakibatkan pelanggan (customer) akan kecewa dikarenakan kualitas pelayanan perusahaan tidak baik. Tujuan penulisan artikel ini adalah untuk mendapatkan desain jaringan distribusi yang baik pada bisnis yang berbasis e commerce. Dengan demikian dapat ditentukan model jaringan distribusi yang baik dengan pendekatan desain jaringan distribusi dan memberikan kualitas pelayanan yang lebih baik melalui jangka waktu pengiriman peralatan dan material sampai di lokasi konsumen, tetapi juga penekanan biaya yang dapat memberikan harga yang lebih bersaing kepada calon calon konsumen.

Industri di indonesia saat ini menghadapi tantangan yang semakin berat dari masa-ke masa seiring dengan pasar globalisasi yang semakin pesat dan berubah-ubah. Berkembangnya teknologi informasi dan tuntutan pelanggan yang semakin tinggi. Persaingan saat ini bukan lagi persaingan antar perusahaan akan tetapi perrsaingan antar jaringan rantai pasok (supply chain network). Rantai pasok (supply chain) adalah bagian yang memegang peranan penting di setiap perusahaan yang ingin memenangkan persaingan, sehingga rantai pasok memerankan peran penting terhadap persediaan bagi dunia insdutri, baik manufaktur dan jasa.

Persaingan bisnis saat ini semakin ketat seiring dengan pasar yang semakin mendunia, berkembangnya teknologi informasi dan tuntutan pelanggan yang semakin tinggi khususnya di bidang perindustrian dalam menghadapi tantangan yang berubah-ubah dan semakin berat dari masa ke masa. Persaingan bisnis saat ini bukan lagi persaingan antar perusahaan akan tetapi persaingan antar jaringan rantai pasok (supply chain network). Fokus bisnis rantai pasok tradisional adalah pada pengiriman barang dan transaksi pengiriman barang, sedangkan pada tahun 2000an telah berubah fokus bisnisnya, yaitu pada profit yang menggunakan teknologi informasi (Kuei, Madu, Lin, \& Chow, 2002). Terdapat 5 variabel logistik yang mempengaruhi biaya logistik, yaitu order, range/product, demand/market, logistic structure, dan general infrastructure (Grando \& Gosso, 2014)

Supply chain merupakan jaringan perusahan-perusahaan yang secara bersama-sama bekerja untuk menciptakan dan menghantarkan suatu produk ke tangan pemakai akhir. Perusahaan-perusahaan tersebut biasanya termasuk pemasok, pabrik distributor, toko, ritel, serta perusahaan-perusahaan pendukung seperti perusahaan jasa logistik. Berdasarkan penelitian yang dilakukan oleh Bag, Telukdarie, Pretorius, dan Gupta, (2018), konsep industry 4.0 dapat digabungkan dengan konsep rantai pasok berkelanjutan (sustainable supply chain), konsep internet of things (IoT) dapat digabungkan 
dengan pengembangan berkelanjutan (sustainable development), embedded systems dapat digabungkan dengan operasional berkelanjutan (sustainable operations), dan cyber physical system dapat digabungkan dengan logistik cerdas (smart logistics). Rantai pasok adalah bagian yang memegang peranan penting di setiap perusahaan yang ingin memenangkan persaingan. Oleh karena itu harus ada penilaian terhadap kinerja rantai pasok di setiap tahunnya sehingga terjadi perbaikan yang terus menerus pada aliran rantai pasok pada perusahaan tersebut. Dengan adanya pengukuran kinerja yang efektif akan mampu mengungkapkan penyesuaian apa yang diperlukan dalam aliran rantai pasok perusahaan. Pengukuran kinerja pada rantai pasok melibatkan proses internal dan juga kinerja yang diharapkan dari perusahaan anggota rantai pasok lainnya. Dengan rantai belakang adalah pemasok (supplier) dan rantai depan adalah pelanggan. Revolusi kualitas pada akhir tahun 1980 dan revolusi rantai pasok pada awal tahun 1990 telah memperjelas bahwa perusahaan yang ingin memenangkan persaingan perlu mengintegrasikan pengelolaan lingkungan dengan aktivitas operasi yang dilakukan secara kontinyu. Selain itu, permintaan pasar global dan tekanan pemerintah mendorong bisnis menjadi lebih berkelanjutan (sustainable)

\section{METODE}

\subsection{Model Saluran Distribusi}

\subsubsection{Saluran Distribusi Model Lama}

Menurut Suryanto, (2016), saluran distribusi dibagi 2 tipe, yaitu saluran tradisional dan saluran modern. 1) saluran tradisional adalah tempat penjualannya masih menggunakan tempat tradisional, seperti warung, gerobak, dan pasar desa, semua tempat tersebut dapat berpindah tempat atau tidak permanen. 2) saluran modern adalah tempat penjualannya telah menggunakan tempat untuk berjualannya yang permanen, seperti toko/outlet dan gerai atau ritel.

\subsubsection{Saluran Distribusi Model Baru}

Masih menurut Suryanto, (2016), perkembangan perusahaan distribusi mengalami kemajuan seiring dengan kemajuan teknologi saat ini. Pada saat ini, banyak tersedia saluran distribusi yang menerapkan atau melayani berbagai macam kebutuhan konsumen.

Contoh model distribusi seperti ini adalah produk es krim dapat dibeli apotek; memesan tiket pesawat atau kereta api; dapat melalui call center atau internet; membeli polis asuransi dapat dibeli di travel agent. 


\subsection{Desain Jaringan Distribusi}

\subsubsection{Penyimpanan Produk Dengan Pengiriman Langsung}

Menurut Chopra dan Meindln (2013), Tipe distribusi ini (Gambar 1), Dalam opsi ini, produk dikirim langsung dari pabrik ke pelanggan akhir, melewati pengecer (yang mengambil pesanan dan memulai permintaan pengiriman). Opsi ini juga disebut sebagai pengiriman drop. Pengecer tidak membawa inventaris. Informasi mengalir dari pelanggan, melalui pengecer, ke pabrik, dan produk dikirim langsung dari pabrik ke pelanggan seperti yang ditunjukkan pada Gambar1. Pengecer online seperti eBags dan Nordstrom.com menggunakan pengiriman langsung ke konsumen akhir, e-Bags menyimpan beberapa tas dalam satu tempat persediaan. Nordstrom membawa beberapa produk dalam tempat persediaan dan menggunakan model kapal laut untuk pengiriman. W. Grainger juga menggunakan pengiriman langsung untuk mengirimkan barang-barang yang agak sulit dikirim, ke pelanggan.

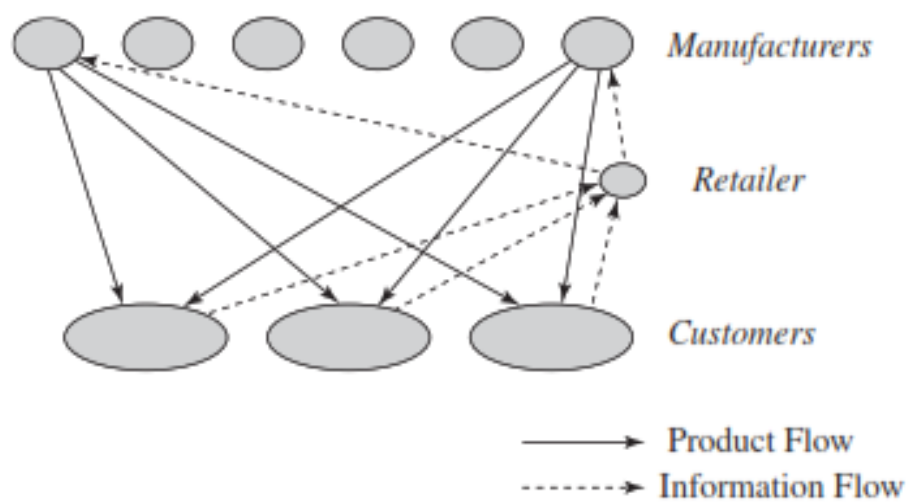

Gambar 1.

Keuntungan terbesar dari pengiriman langsung adalah kemampuan untuk memusatkan persediaan di pabrik agar bisa dikumpulkan semua permintaan di semua pengecer yang akan disuplai. Sehingga, rantai pasokan mampu menyediakan tingkat ketersediaan produk yang tinggi dengan tingkat persediaan yang lebih rendah. Masalah utama terkait dengan drop-pengiriman adalah struktur kepemilikan persediaan di pabrik. Jika ditentukan porsi inventaris di pabrik dialokasikan untuk pengecer individual, hanya ada sedikit manfaatnya agregasi meskipun persediaan secara fisik dikumpulkan. Manfaat agregasi dapat dicapai jika pabrikan dapat mengalokasikan setidaknya sebagian dari inventori yang tersedia di seluruh pengecer berdasarkan kebutuhan. Manfaat dari sentralisasi paling besar adalah untuk permintaan bernilai tinggi dan rendah serta pada permintaan yang tidak terduga 


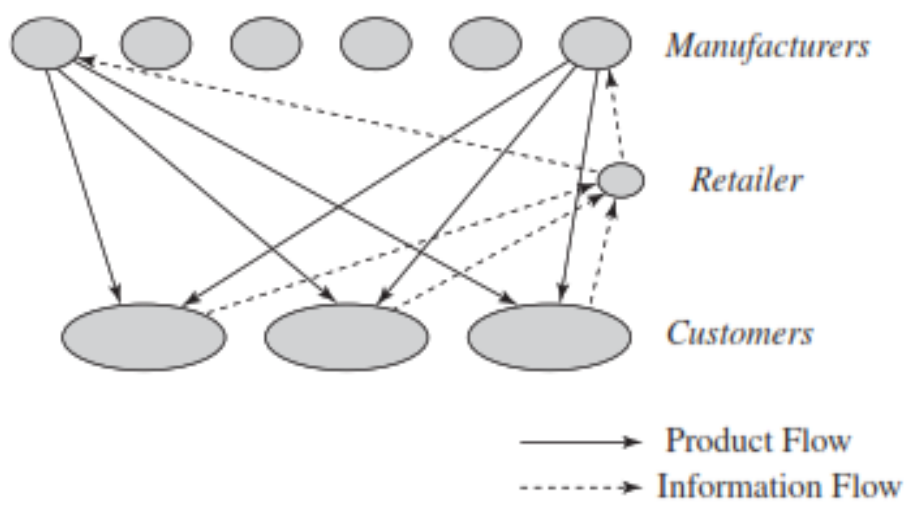

Gambar 1.

\subsubsection{Penyimpanan Produk Dengan Pengiriman Langsung dan Penggabungan dalam Satu Transit}

Menurut Chopra dan Meindln (2013), Tidak seperti pengiriman langsung (drop) murni, di mana setiap produk dalam pesanan dikirim langsung dari pabrikan untuk pelanggan akhir, dalam perjalanannya digabungkan potongan-potongan pesanan yang berasal lokasi berbeda sehingga pelanggan mendapat satu kiriman. Informasi dan arus produk untuk jaringan gabungan in-transit ditunjukkan pada Gambar 2. Model penggabungan ini telah digunakan oleh Dell dan dapat juga digunakan oleh perusahaan yang menerapkan pengiriman langsung. Sebagai contoh, ketika seorang pelanggan memesan PC dari Dell bersama dengan monitor Sony, pembawa paket mengambil PC dari pabrik Dell dan PC monitor dari pabrik Sony; kemudian menggabungkan keduanya sebuah di hub sebelum melakukan pengiriman tunggal kepada pelanggan.

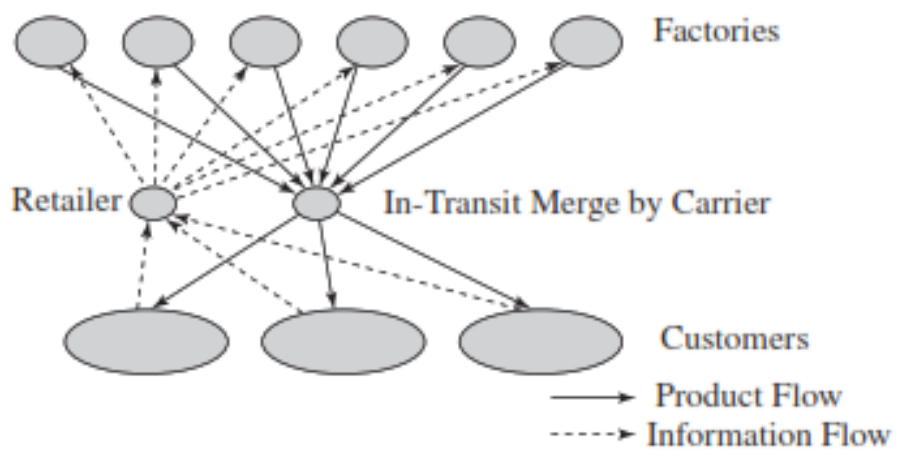

Gambar 2.

\subsubsection{Penyimpanan Distributor Dengan Menggunakan Carrier Delivery}

Menurut Chopra dan Meindln (2013), Di bawah opsi ini, persediaan tidak dipegang oleh produsen di pabrik tetapi dipegang oleh distributor/pengecer di gudang perantara, dan pengangkutan paket digunakan untuk transportasi produk dari lokasi perantara ke pelanggan akhir. Amazon dan distributor industry seperti W. Grainger dan McMaster-Carr telah menggunakan pendekatan ini yang 
dikombinasikan dengan pengiriman langsung dari produsen (atau distributor). Informasi dan aliran produk saat menggunakan penyimpanan distributor dengan pengiriman oleh pembawa paket ditunjukkan pada Gambar 3.

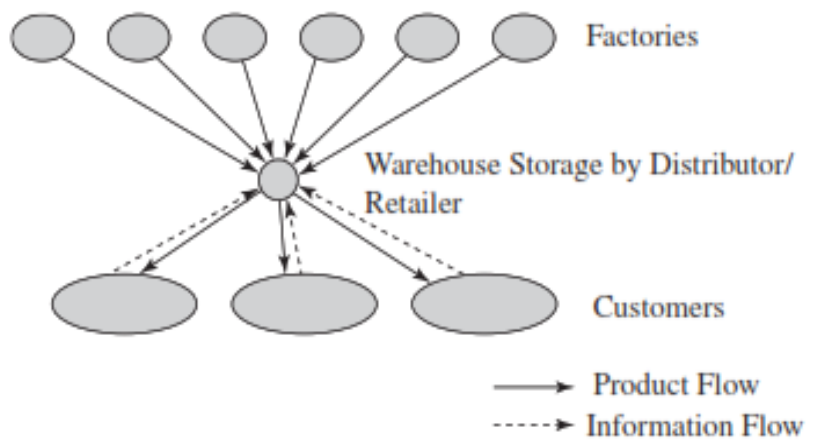

Gambar 3.

Penyimpanan distributor membutuhkan tingkat inventaris yang lebih tinggi karena kehilangan agregasi. Dari perspektif inventaris, penyimpanan distributor menjadi masuk akal untuk produk dengan permintaan yang cenderung tinggi. Ini terlihat dalam operasi Amazon dan W. Grainger. Mereka hanya menimbun barang yang sirkulasinya lambat hingga yang cepat di gudang mereka, dengan cara barang yang sirkulasinya lambat dikirim kembali terlebih dahulu ke hulu. Dalam beberapa kasus, penundaan produk diferensiasi dapat diimplementasikan dengan model penyimpanan distributor, tetapi itu mengharuskan gudang mengembangkan beberapa kemampuan perakitan.

\subsubsection{Penyimpanan Distributor dengan Menggunakan Pengiriman di Titik Terdekat}

Menurut Chopra dan Meindln (2013), Pengiriman jarak jauh mengacu pada distributor/pengecer yang mengantarkan produk ke rumah pelanggan menggunakan pembawa paket. Sebagai contoh, Webvan, Peapod, dan Albertsons telah menggunakan pengiriman jarak jauh dalam industri grosir. Amazon telah meluncurkan "pengiriman ekspres lokal" untuk memberikan layanan pengiriman di hari yang sama kepada pelanggan. Perusahaan seperti Kozmo dan Urbanfetch mencoba mengatur pengiriman menggunakan rumah jaringan untuk berbagai produk, tetapi mereka gagal mempertahankannya.

Industri suku cadang otomotif adalah contoh yang merapkannya, di mana penyimpanan distributor dengan pengiriman jarak tempuh terakhir adalah model yang dominan. Hal tersebut menjadi terlalu mahal bagi dealer untuk membawa semua suku cadang yang ada di dalam persediaan. Dengan demikian, produsen peralatan asli (OEM) cenderung membawa sebagian besar suku cadang di pusat distribusi lokal yang biasanya terletak tidak lebih dari beberapa jam perjalanan dari dealer mereka dan sering dikelola oleh pihak ketiga. Lingkungan setempat, yaitu pusat distribusi bertanggung jawab untuk 
mengirimkan suku cadang yang dibutuhkan ke sejumlah dealer dan pengiriman berbagai macam merek per hari. Tidak seperti pengiriman paket operator, pengiriman jarak tempuh terakhir (last mile delivery) membutuhkan gudang distributor yang lebih dekat dengan pelanggan. Mengingat radius yang terbatas tersebut, maka harus dilayani dengan pengiriman last-mile delivery. Penyimpanan gudang dengan jaringan pengiriman last-mile seperti yang ditunjukkan pada Gambar 4.

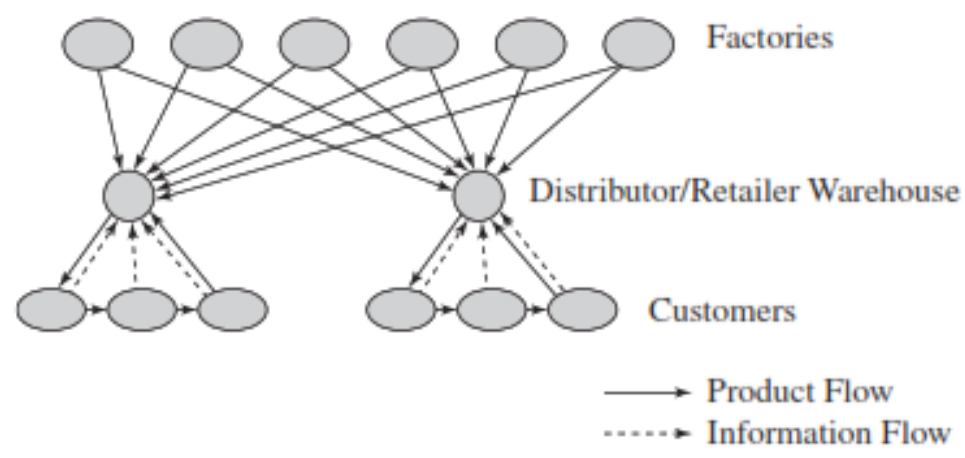

Gambar 4.

\subsubsection{Penyimpanan Hasil produksi atau Distributor Dengan Penjemputan Pelanggan}

Menurut Chopra dan Meindln (2013), dalam pendekatan ini, persediaan disimpan di gudang pabrik atau distributor, tetapi pelanggan melakukan pemesanan secara online atau di telepon dan kemudian melakukan perjalanan ke tempat pengambilan yang ditunjuk untuk mengumpulkan barang dagangan mereka. Pesanan dikirimkan dari lokasi penyimpanan ke titik pengambilan sebagai dibutuhkan. Contohnya termasuk 7dream.com dan Otoriyose-bin, dioperasikan oleh Seven-Eleven Jepang, yang memungkinkan pelanggan untuk mengambil pesanan online di toko yang ditunjuk. Bisnis-ke-bisnis Contoh (B2B) adalah W.W. Grainger, yang pelanggannya dapat mengambil pesanan mereka di salah satu W.W. Gerai ritel Grainger. Beberapa item disimpan di lokasi pengambilan, sedangkan yang lain mungkin datang dari lokasi pusat. Dalam kasus 7dream.com, pesanan dikirimkan dari produsen atau distributor gudang ke lokasi pengambilan. Pada 2007, Wal-Mart meluncurkan "Site to Store" layanan yang memungkinkan pelanggan memesan ribuan produk secara online di Walmart.com dan miliki mereka dikirim gratis ke toko Wal-Mart setempat. Barang tiba di toko 7 hingga 10 hari kerja setelah pesanan diproses, dan pelanggan menerima pemberitahuan email saat pesanan mereka siap untuk diambil.

Informasi dan aliran produk yang ditunjukkan pada Gambar 5 serupa dengan yang ada di Jaringan Seven-Eleven Jepang. Seven-Eleven memiliki pusat distribusi di mana produk dari pabrikan berlabuh dan dikirim ke outlet ritel setiap hari. Pengecer online mengirimkan pesanan melalui Seven-Eleven dapat diperlakukan sebagai salah satu produsen, dengan pengiriman berlabuh dan dikirim ke outlet 
Seven-Eleven yang sesuai. Berfungsi sebagai outlet untuk pesanan online memungkinkan SevenEleven untuk meningkatkan pemanfaatan aset logistik yang ada.

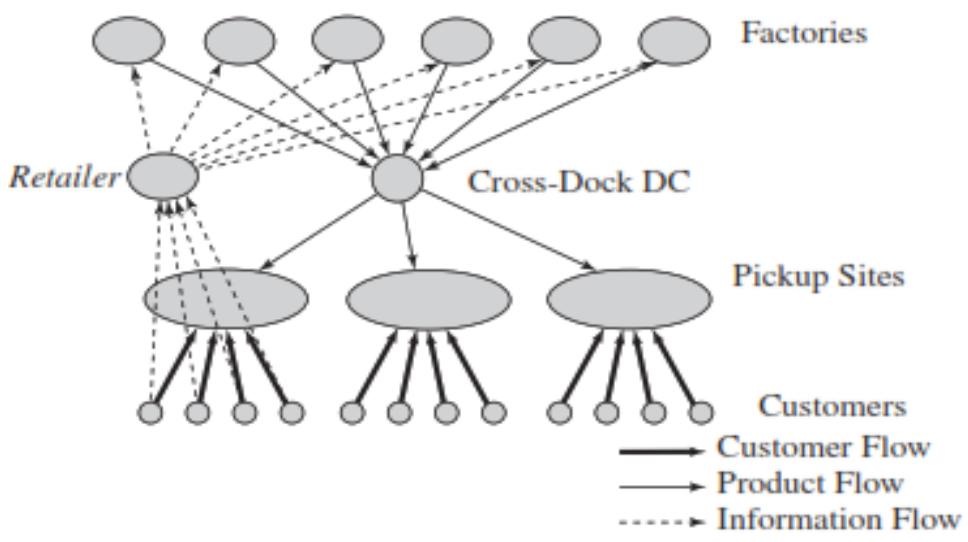

Gambar 5.

\subsubsection{Penyimpanan Ritel Dengan Penjemputan Pelanggan}

Menurut Chopra dan Meindln (2013), Dalam opsi ini, sering dipandang sebagai jenis rantai pasokan yang paling tradisional, persediaan disimpan secara lokal di toko ritel. Pelanggan berjalan ke toko ritel atau memesan secara online atau melalui telepon dan mengambilnya di toko ritel. Contoh perusahaan yang menawarkan beberapa opsi pemesanan penempatan termasuk Albertsons, yang menggunakan bagian dari fasilitas sebagai toko kelontong dan bagian sebagai pusat pemenuhan online. Pelanggan dapat berjalan ke toko atau memesan secara online. Contoh B2B adalah W.W. Grainger: Pelanggan dapat memesan secara online, melalui telepon, atau secara langsung dan mengambil pesanan mereka di salah satu dari W. Gerai ritel Grainger. Albertsons menyimpan inventarisnya di lokasi pengambilan itu sendiri; W. Grainger menyimpan beberapa barang di lokasi pengambilan, sedangkan yang lain mungkin berasal dari lokasi pusat.

Penyimpanan lokal meningkatkan biaya inventaris karena kurangnya agregasi. Untuk yang cepat barang yang bergerak sangat cepat, bagaimanapun, ada peningkatan marginal dalam persediaan bahkan dengan barang lokal penyimpanan. Albertsons menggunakan penyimpanan lokal karena sebagian besar produknya bergerak relatif cepat dan disimpan di supermarket dalam hal apa pun. Demikian pula, W. Grainger menyimpan inventarisnya barangyang bergerak cepat di lokasi pengambilan, sedangkan item yang bergerak lambat disimpan di pusat gudang.

Tipe ini adalah tipe tradisional dari semua jenis distribusi yang ada dalam supply chain, inventori disimpan di dalam toko. Pelanggan datang ke toko untuk melakukan pemesanan dan pembelian. 
Keuntungannya adalah biaya transportasi yang cukup murah, kekuranggannya adalah biaya inventori yang cukup tinggi.

Pada perusahaan manufaktur, persediaan terdiri dari persediaan bahan baku, barang dalam proses dan persediaan barang jadi. Manajemen persediaan yang akan dibahas disini lebih difokuskan pada manajemen persediaan bahan baku. Manajemen persediaan bahan baku bertujuan agar tingkat persediaan bahan baku cukup, tidak terlalu banyak tetapi tidak terlalu sedikit, sehingga biaya bahan baku ekonomis dan perusahaan tidak kehilangan kesempatan untuk melayani penjualan karena kurangnya persediaan bahan baku.

\section{Hasil dan Pembahasan}

Dari enam bentuk desain jaringan distribusi pada bagian 2 diatas, pendekatan yang terbaik untuk penerapan desain jaringan distribusi berbasis e-commerce, adalah last mile delivery dan carrier delivery. Alasan pemilihan dua model jaringan tersebut adalah, implementasi nya langsung ke pelanggan atau pemakai dan lebih efektif.

\subsection{Pemilihan Desain Jaringan Distribusi}

Desain jaringan distribusi perlu mempertimbangkan karakteristik produk serta persyaratan jaringan saat memutuskan jaringan pengiriman yang sesuai. Berbagai jaringan yang dipertimbangkan sebelumnya memiliki kekuatan dan kelemahan yang berbeda. Pada Tabel 1, berbagai jaringan pengiriman diperingkat relatif terhadap satu sama lain sepanjang dimensi kinerja yang berbeda. Nilai 1 menunjukkan kinerja terbaik sepanjang dimensi yang diberikan.

Tabel 1.

\begin{tabular}{|c|c|c|c|c|c|c|}
\hline & $\begin{array}{l}\text { Retail } \\
\text { Storage } \\
\text { with } \\
\text { Customer } \\
\text { Pickup }\end{array}$ & $\begin{array}{l}\text { Manufacturer } \\
\text { Storage with } \\
\text { Direct } \\
\text { Shipping }\end{array}$ & $\begin{array}{l}\text { Manufacturer } \\
\text { Storage with } \\
\text { In-Transit } \\
\text { Merge }\end{array}$ & $\begin{array}{l}\text { Distributor } \\
\text { Storage with } \\
\text { Package } \\
\text { Carrier } \\
\text { Delivery }\end{array}$ & $\begin{array}{l}\text { Distributor } \\
\text { Storage with } \\
\text { Last-Mile } \\
\text { Delivery }\end{array}$ & $\begin{array}{l}\text { Manufacturer } \\
\text { Storage with } \\
\text { Pickup }\end{array}$ \\
\hline Response time & 1 & 4 & 4 & 3 & 2 & 4 \\
\hline Product variety & 4 & 1 & 1 & 2 & 3 & 1 \\
\hline Product availability & 4 & 1 & 1 & 2 & 3 & 1 \\
\hline $\begin{array}{l}\text { Customer } \\
\text { experience }\end{array}$ & $\begin{array}{l}\text { Varies from } \\
1 \text { to } 5\end{array}$ & 4 & 3 & 2 & 1 & 5 \\
\hline Time to market & 4 & 1 & 1 & 2 & 3 & 1 \\
\hline Order visibility & 1 & 5 & 4 & 3 & 2 & 6 \\
\hline Returnability & 1 & 5 & 5 & 4 & 3 & 2 \\
\hline Inventory & 4 & 1 & 1 & 2 & 3 & 1 \\
\hline Transportation & 1 & 4 & 3 & 2 & 5 & 1 \\
\hline Facility and handling & 6 & 1 & 2 & 3 & 4 & 5 \\
\hline Information & 1 & 4 & 4 & 3 & 2 & 5 \\
\hline
\end{tabular}




\subsection{Penyimpanan Distributor dengan Menggunakan Pengiriman di Titik Terdekat (Last mile delivery)}

Pengiriman di titik terdekat adalah langkah terakhir dari rantai pasokan $e$-commerce. Ini adalah saat pelanggan menerima barang-barang mereka dan umumnya merupakan bagian yang paling berharga, menantang dan paling tidak efisien dalam rantai pasokan. Sebagian besar tantangan ini berkaitan dengan harapan tinggi pelanggan berbasis online. Ini termasuk pengiriman pada hari yang sama atau sesuai permintaan, sehingga meningkatkan total biaya pengiriman untuk pengecer; visibilitas waktunyata atas pengiriman, termasuk kemampuan untuk melacak pengemudi menggunakan peta waktunyata; dan pengalaman pengiriman yang lancar sejak pesanan ditempatkan sampai bagaimana itu harus disampaikan.

Last-mile delivery merupakan desain jaringan distribusi dimana dalam pengiriman barangnya, pihak distributor atau retailer tidak menggunakan jasa pengiriman pihak ketiga, tetapi langsung dikirimkan oleh mereka dari rumah ke rumah. Amazon sudah menggunakan model ini khusus untuk produkproduk makanan mereka.

Syarat jaringan distribusi dengan model ini adalah fasilitas persediaan barangnya harus benar-benar mendekati pengguna, dibandingkan model penyimpanan distributor (distributor storage) biasa. Desain jaringan distribusi ini dapat dilihat pada Gambar 6.

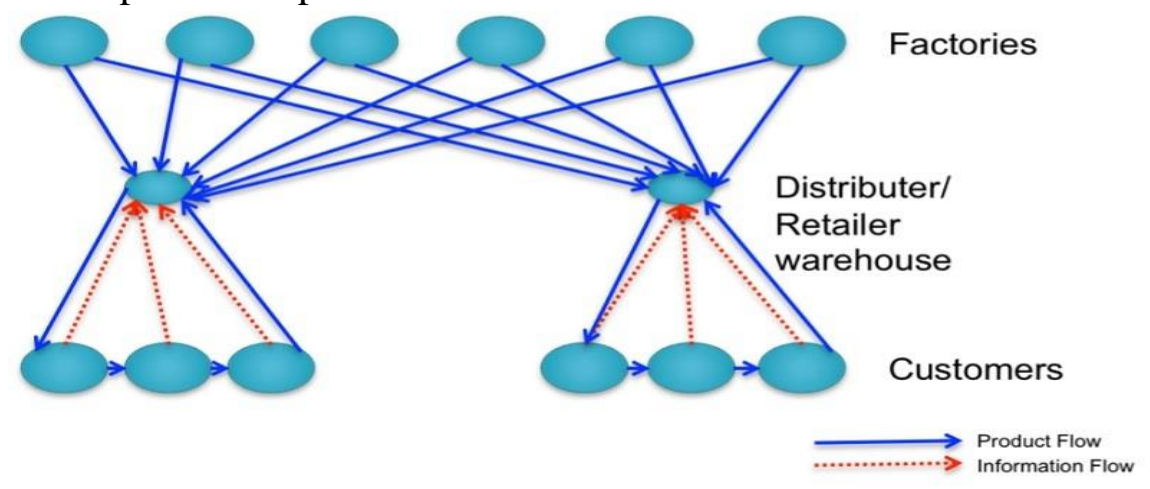

Gambar 6. Desain jaringan distribusi last mile delivery

\subsection{Penyimpanan Distributor Dengan Menggunakan Carrier Delivery}

Biaya transportasi agak lebih rendah untuk penyimpanan distributor dibandingkan dengan pabrik penyimpanan karena moda transportasi ekonomis dapat digunakan untuk pengiriman masuk ke gudang, yang lebih dekat ke pelanggan. Berbeda dengan pabrikanpenyimpanan, di mana beberapa pengiriman mungkin perlu dilakukan untuk satu pesanan pelanggan beberapa barang, penyimpanan distributor memungkinkan pesanan keluar ke pelanggan untuk dibundel menjadi sebuah pengiriman tunggal, selanjutnya mengurangi biaya transportasi. Penyimpanan distributor memberikan penghematan pada transportasi barang yang bergerak lebih cepat relatif terhadap penyimpanan pabrikan. 
Dibandingkan dengan penyimpanan barang hasil produksi, biaya fasilitas (untuk pergudangan) agak lebih tinggi dengan penyimpanan distributor karena kehilangan kemampuan dalam mengumpulkan barang (agregasi). Biaya pemrosesan dan penanganan adalah sebanding dengan penyimpanan barang hasil produksi, kecuali pabrik dapat mengirim ke pelanggan akhir secara langsung dari jalur produksi. Dalam hal ini, penyimpanan distributor memiliki biaya pemrosesan yang lebih tinggi. Dari perspektif biaya fasilitas, penyimpanan distributor tidak sesuai untuk barang yang bergerak sangat lambat.

Infrastruktur informasi yang dibutuhkan dengan penyimpanan distributor jauh lebih sedikit kompleks daripada yang dibutuhkan dengan penyimpanan pabrikan (manufacture). Gudang distributor berfungsi sebagai sebuah penyangga antara pelanggan dan produsen, mengurangi kebutuhan untuk mengoordinasikan keduanya sama sekali. Dibutuhkan visibilitas waktu nyata antara pelanggan dan gudang visibilitas waktu-nyata antara pelanggan dan produsen tidak. Visibilitas antara gudang distributor dan pabrikan dapat dicapai dengan biaya yang jauh lebih rendah daripada waktu nyata visibilitas antara pelanggan dan produsen.

Waktu respons di bawah penyimpanan distributor lebih baik daripada di bawah penyimpanan pabrik karena gudang distributor, rata-rata, lebih dekat ke pelanggan, dan seluruh pesanan digabungkan pada gudang sebelum dikirim. Amazon, misalnya, memproses sebagian besar gudang yang disimpan barang dalam satu hari dan kemudian dibutuhkan tiga hingga lima hari kerja menggunakan transportasi darat untuk pesanan untuk mencapai pelanggan. W. Grainger memproses pesanan pelanggan pada hari yang sama dan memiliki gudang yang cukup untuk mengantarkan sebagian besar pesanan keesokan harinya menggunakan transportasi darat. Gudang batas penyimpanan sampai batas tertentu berbagai produk yang dapat ditawarkan. W. Grainger tidak menyimpan barang-barang dengan permintaan rendah di gudang, bergantung pada produsen untuk mengirim barang-barang tersebut produk kepada pelanggan. Desain jaringan distribusi ini dapat dilihat pada Gambar 7.

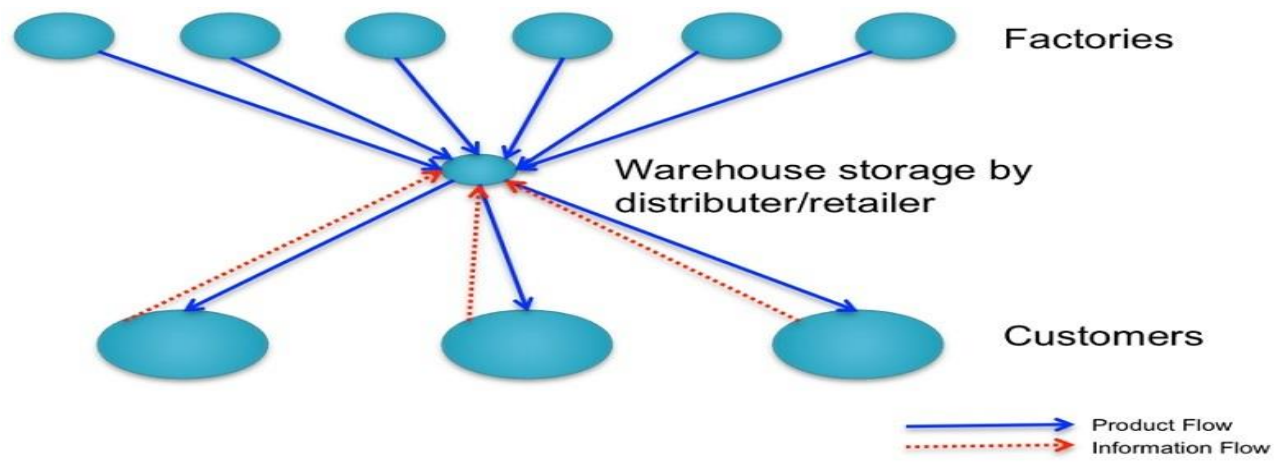

Gambar 7. Desain jaringan distribusi carrier delivery 


\section{SIMPULAN}

Manajemen rantai pasok, menyarankan agar waktu dipakai sebagai metric dalam pengukuran kinerja dikarenakan pengontrolan dan pemendekan waktu dapat meningkatkan kualitas, mengurangi biaya dan meningkatkan respon terhadap kebutuhan pelanggan dan produktivitas.

Untuk mendapatkan desain jaringan distribusi yang baik pada bisnis yang berbasis e commerce, diperlukan dimensi waktu responsif yang cepat, adanya variasi produk, adanya ketersediaan produk, pengalaman terhadap pelanggan. Selain itu, menguasai pasar, menguasai kehandalan dan kekurangan produk, inventori, tingkat pengembalian yang tinggi, transportasi yang handal, fasilitas dan penanganan barang di tempat penyimpanan yang baik, dan terakhir informasi bahan baku, produk, dan pelanggan yang handal.

Dengan demikian dapat ditentukan model jaringan distribusi yang baik dengan pendekatan desain jaringan distribusi dan memberikan kualitas pelayanan yang lebih baik melalui jangka waktu pengiriman peralatan dan material sampai di lokasi konsumen, tetapi juga penekanan biaya yang dapat memberikan harga yang lebih bersaing kepada calon calon konsumen.

Dari 6 desain jaringan distribusi, pendekatan model jaringan last mile delivery dan carrier delivery, tepat diterapkan dalam jaringan distribusi e-commerce. Perusahaan internasional yang telah menerapkan model jaringan last mile delivery dan carrier delivery adalah Amazon 


\section{DAFTAR PUSTAKA}

[1] Bag, S., Telukdarie, A., Pretorius, J. H. C., \& Gupta, S. (2018). Industry 4.0 and supply chain sustainability: framework and future research directions. Benchmarking. https://doi.org/10.1108/BIJ-03-2018-0056

[2] Chopra, S., Meindl, M. (2013). Supply chain management : strategy, planning, and operation. Pearson, Fifth Edition, New Jersey, USA

[3] Kuei, C. H., Madu, C. N., Lin, C., \& Chow, W. S. (2002). Developing supply chain strategies based on the survey of supply chain quality and technology management. International Journal of Quality and Reliability Management, 19(7), 889-901. https://doi.org/10.1108/02656710210434793.

[4] Grando, A., \& Gosso, M. (2014). ELECTRONIC COMMERCE AND LOGISTICS: THE LAST MILE DILEMMA REFERENCE FRAMEWORK AND SIMULATION. Revista de Administração e Inovação, São Paulo, 2(2),77-97

[5] Suryanto, M., H. (2016). Sistem Operasional Manajemen Distribusi. PT Grasindo, Jakarta 